\title{
Malaria in Pregnancy: Intermittent Preventive Treatment Coverage Among Women of the Bamenda Health District, Cameroon
}

\author{
Ngwene Hycentha Diengou ${ }^{1,2 *}$, Vecheusi Zennobia Viyoff ${ }^{1}$ and NgwayuClaude Nkfusai $^{1}$ \\ ${ }^{1}$ Department of Microbiology and Parasitology,University of Buea, Cameroon \\ ${ }^{2}$ Institute of Medical Research and Medicinal Plant Studies, Ministry of Scientific Research and Innovation, Cameroon
}

Submission: October 26, 2018; Published: November 15, 2018

*Corresponding author: Ngwene Hycentha Diengou, Department of Microbiology and Parasitology, Faculty of Science, University of Buea, Buea, Cameroon

Abstract

Malaria is endemic throughout most of the tropics. WHO (2013) states that more than 207 million people developed symptomatic malaria in 2012. Each year approximately fifty million women living in malaria endemic countries throughout the world become pregnant, of whom over half live in tropical areas of Africa with intense transmission of $P$ falciparum. We aimed at finding the IPTp coverage in the peri urban and urban areas of Bamenda Health District. We found that out of the 400 women, 381 reported to have taken SP while 19 women did not receive IPT.

\section{Introduction}

Malaria infection in a pregnant woman is associated with poor pregnancy outcome and an increased risk of complications which necessitates early diagnosis and proper management of malaria cases. The success of malaria case management depends, in part, on adherence to the official recommendations [1].

Strategies for controlling malaria during pregnancy in Subsaharan Africa (SSA) often include treatment of the disease and resulting anaemia with chemoprophylaxis[2].The combination of Quinine and Clindamycine was recommended by Hay SI, et al. [3]. for the treatment of malaria in the first trimester of pregnancy. This combination has proven highly efficacious against multi drug resistant strains of $P$ falciparum with a 42 day cure rates of $100 \%$ in one study [3]. In 2006, WHO published guidelines recommending artemisinin combination therapies (ACTs) for the treatment of malaria in the second and third trimester of pregnancy.

\section{Study Designed}

A cross sectional study among 400 women in the Bamenda Health District, Mezam Division, North West Region. Questionnaires were given and analyzed almost immediately and the results presented in frequency distribution tables.

Result

\section{Demographic characteristics}

Table 1: Socio-demographic characteristic of the women.

\begin{tabular}{|c|c|c|c|c|}
\hline \multicolumn{2}{|c|}{ Variable N=400 } & Urban 65.5\% (N=262) & Periurban 34.5\% (N=138) & Chi Square (P-Value) \\
\hline \multirow{4}{*}{ Age group } & $21-25$ & $11.5 \%(30)$ & $18.8 \%(26)$ & 4.21 \\
\cline { 2 - 5 } & $\geq 25$ & $36.3 \%(95)$ & $34.8 \%(48)$ & $(0.122)$ \\
\cline { 2 - 5 } & $\leq 20$ & $52.3 \%(137)$ & $46.4 \%(64)$ & \\
\cline { 2 - 5 } & Single/widowed/divorced & $21.4 \%(56)$ & $18.8 \%(26)$ & 0.356 \\
\cline { 2 - 5 } Material Status & Married/ cohabiting & $78.6 \%(206)$ & $81.2 \%(112)$ & $(0.323)$ \\
\hline
\end{tabular}


Journal of Gynecology and Women's Health

\begin{tabular}{|c|c|c|c|c|}
\hline \multirow{5}{*}{ Occupation } & Student & $21.4 \%(56)$ & $25.4 \%(35)$ & \\
\hline & House wife & $24.4 \%(64)$ & $23.2 \%(32)$ & \\
\hline & Farmer & $1.9 \%(5)$ & $13.0 \%(18)$ & *25.767 \\
\hline & Trader & $34.7 \%(91)$ & $29.7 \%(41)$ & $(0.001)$ \\
\hline & Civil servant & $17.6 \%(46)$ & $8.7 \%(12)$ & \\
\hline \multirow{3}{*}{ Educational Level } & $\leq$ Primary education & $23.3 \%(61)$ & $36.2 \%(50)$ & \\
\hline & Secondary education & $52.3 \%(137)$ & $49.3 \%(68)$ & * 9.871 \\
\hline & Higher education & $24.4 \%(64)$ & $14.5 \%(20)$ & $(0.007)$ \\
\hline \multirow{3}{*}{ Trimester at 1 st ANC } & First trimester (0-13) & $40.8 \%(107)$ & $26.8 \%(37)$ & \\
\hline & Second trimester (14-25) & $54.6 \%(143)$ & $71.0 \%(98)$ & 5.49 \\
\hline & Third trimester (26-37) & $4.6 \%(12)$ & $2.2 \%(3)$ & $(0.064)$ \\
\hline \multirow{3}{*}{ Parity } & Nulliparous & $34.0 \%(89)$ & $31.9 \%(44)$ & \\
\hline & Primiparous & $28.6 \%(75)$ & $26.8 \%(37)$ & 0.579 \\
\hline & Multiparous & $37.4 \%(98)$ & $41.3 \%(57)$ & $(0.749)$ \\
\hline \multirow{2}{*}{ ITN use } & Yes & $85.5 \%(224)$ & $86.2 \%(119)$ & 3.734 \\
\hline & No & $14.5 \%(38)$ & $13.8 \%(19)$ & $(0.443)$ \\
\hline \multirow{2}{*}{ Religion } & Christian & $96.6 \%(253)$ & $92.8 \%(128)$ & 2.902 \\
\hline & Non-Christian & $3.4 \%(9)$ & $7.2 \%(10)$ & $(0.075)$ \\
\hline
\end{tabular}

* $=$ significant

A total of 400 women enrolled for the study participated by filling the questionnaires giving a response rate of $100 \%, 262$ from urban areas and 138 from the peri urban areas. The age range of the respondents was between 15-43 years with a mean age of $26.149 \pm 4.868$ years for urban areas and $25.522 \pm 5.352$ for the peri urban areas(Table 1).

\section{IPTp coverage for urban and peri urban areas}

Out of the 400 women, 381 reported to have taken SP while 19 women did not receive IPT. Of the 19 who did not receive IPTp, 3 women were allergic to sulphonamides while 2 were on cotrimoxazle. Of the total population, $65.5 \%$ of the women were from the urban areas and $34.5 \%$ from the peri urban areas. The urban areas had a coverage of $95.8 \%$ for at least one dose and the peri urban a coverage of $94.2 \%$. The IPTp coverage is shown below for the Urban and peri urban areas of BHD(Table 2).

Table 2: IPTp coverage for urban and peri urban areas.

\begin{tabular}{|c|c|c|c|c|}
\hline IPT & Urban\% (n) & $\begin{array}{c}\text { Peri } \\
\text { urban\%(n) }\end{array}$ & Total \%(n) & $\begin{array}{c}\text { Chisquare } \\
\text { (P-Value) }\end{array}$ \\
\hline Yes & $95.8(251)$ & $94.2(130)$ & $95.3 \%(381)$ & \\
\hline No & $4.2(11)$ & $5.8(8)$ & $4.8 \%(19)$ & $0.511(0.314)$ \\
\hline Total & 262 & 138 & $100 \%(400)$ & \\
\hline
\end{tabular}

\section{Discussion}

The study showed that IPTp coverage for at least one dose was $95.3 \%$ which was similar to studies by Anchang-Kimbi JK, et al.[4] that showed coverage of $90 \%$ in Mutegene. Among those who took IPTp, 54.9\% received all three doses. This coverage rate of all three doses is similar to what was observed in the Bamenda Health District report for 2013 (54.33\%). The coverage of $95.3 \%$ for at least one dose seen in this study is slightly above $84.60 \%$ that was reported in the Bamenda health district (Bamenda Health District report for malaria, 2013). The actual coverage obtained from women with gestational age above 36 weeks for at least one dose was 95.9\% (95.5\% for urban areas and $97.0 \%$ for peri urban areas). These rates are almost similar to what was observed in Malawi [5]. For these same women, the uptake rate for both groups was highest for those who took all three doses ie $60.1 \%$ for urban and $62.5 \%$ for peri urban. These uptake rates in Bamenda can be attributed to the fact that most of the health facilities practice the policy of direct observed therapy. This is because from our findings, 162 women (61.8\%) and 92 women (67.6\%) from urban and peri urban areas respectively reported to have taken the drug in front of the health provider. This policy was applied equally in both the peri urban and urban areas $(\mathrm{P}=0.472)$. There was no difference in the uptake rates recorded in the urban and peri urban areas $(\mathrm{p}=0.314)$ of Bamenda.

\section{Conclusion}

We can conclude therefore that most pregnant women in the Bamenda Health DistrictCoverage of IPTp for at least one dose is high (95.9\%).

\section{Authors' contributions}

NHD, VZV and NCN conceived and designed the study. NHD implemented the study. NHD, VZV and NCN conducted data analysis. NHD, VZV and NCN interpreted study results: NHD and NCN wrote the first draft of the manuscript. NCN reviewed and corrected the draft manuscript. All authors read and approved the final manuscript. 


\section{Acknowledgement}

We are grateful to all the women who took part in this study.

\section{References}

1. Zurovac D, Rowe AK, Ochola SA, Noor AM, Midia B, et al. (2004) Predictors of the quality of health worker treatment practices for uncomplicated malaria at government health facilities in Kenya. Int J Epidemiol 33(5): 1080-1091.

2. Garner P, Gulmezoglu AM (2006) Drugs for preventing malaria in pregnant women. Cochrane Database System 4: CD000169.
3. Hay SI, Okiro EA, Gething PW, Patil AP, Tatem AJ, et al. (2010) Estimating the global clinical burden of Plasmodium falciparum malaria in 2007. PLoS medicine 7(6): e1000290.

4. Anchang-Kimbi JK, Achidi EA, Apinjoh TO, Mugri RN, Chi HF, et al (2014) Antenatal care visit attendance, intermittent preventive treatment during pregnancy (IPTp) and malaria parasitaemia at delivery. Malaria journal 13(1): 162.

5. Van Eijk AM, Hill J, Alegana VA, Kirui V, Gething PW, et al. (2011) Coverage of malaria protection in pregnant women in sub-Saharan Africa: a synthesis and analysis of national survey data. Lancet Infect Dis 11(3): 190-207.

\section{Your next submission with Juniper Publishers will reach you the below assets}

- Quality Editorial service

- Swift Peer Review

- Reprints availability

- E-prints Service

- Manuscript Podcast for convenient understanding

- Global attainment for your research

- Manuscript accessibility in different formats

( Pdf, E-pub, Full Text, Audio)

- Unceasing customer service

Track the below URL for one-step submission https://juniperpublishers.com/online-submission.php 